\title{
DEVELOPMENT AND VALIDATION OF NEW METHOD FOR THE SIMULTANEOUS ESTIMATION OF CEFTRIAXONE AND TAZOBACTAM USING RP-HPLC
}

\author{
Sridevi Ranjitha Karanam², Y. Rajendra Prasad*1 \\ ${ }^{* 1}$ Principal, Andhra University college of Pharmaceutical sciences, Visakhapatnam, AP. \\ ${ }^{2}$ Aditya college of pharmacy, surampalem, east godavari dt. Andhrapradesh \\ *Corresponding author: ranjitha.karanam@gmail.com
}

\begin{abstract}
The aim of this study is to create and validate a fast, easy-to-use, affordable, sensitive, and accurate method for measuring Ceftriaxone and Tazobactam in bulk and pharmaceutical products using Reversed-Phase High-Performance Liquid Chromatography (RP-HPLC). Waters X-Terra RP-18 column was used with a running phase composed of water: acetonitrile $(40: 60 \mathrm{v} / \mathrm{v})$ at a flow rate of $1.0 \mathrm{ml} / \mathrm{min}$. UV detection was used at a wavelength of $230 \mathrm{~nm}$. Tazobactam and Ceftriaxone correlation coefficients were found to be 0.999 over a concentration range of $1.25-18.75 \mu \mathrm{g} / \mathrm{ml}$ and $10-150 \mu \mathrm{g} / \mathrm{ml}$, respectively. Tazobactam and Ceftriaxone have respective retention times of 3.131 and 2.648 minutes. The run time for separating Tazobactam and Ceftriaxone peaks was 5 minutes. The validation results agreed with what's acceptable and had good limits. This method, proposed as a regular analysis and quality control tool for medications that contain these active drugs either individually or in combination, was evident to be a suitable one.
\end{abstract}

Keywords: HPLC, Tazobactam, Ceftriaxone, Development, Validation.

\section{Introduction}

Ceftriaxone, commercialised under the trade name Rocephin, is a third-generation cephalosporin ${ }^{[1-2]}$ antibiotic ${ }^{[3-5]}$ used for the treatment of a range of bacterial infections. These include middle ear infections, endocarditis ${ }^{[6-7]}$, meningitis ${ }^{[8-9]}$, pneumonia ${ }^{[10-11]}$, bone and joint infections, intra-abdominal infections ${ }^{[12]}$, skin infections ${ }^{[13]}$, urinary tract infections ${ }^{[14]}$, gonorrhea ${ }^{[15]}$, and pelvic inflammatory ${ }^{[16]}$ disease. It is also occasionally administered before surgery and after a bite wound to attempt to avoid infection. Ceftriaxone may be delivered via injection into a vein or into a muscle. Common side effects include soreness at the site of injection and allergic reactions ${ }^{[17]}$. Other potential adverse effects include C. difficile-associated diarrhea ${ }^{[18]}$, hemolytic anaemia ${ }^{[19]}$, gall bladder illness, and seizures ${ }^{[20]}$. It is not suggested in people who have had anaphylaxis ${ }^{[21]}$ to penicillin but may be used in those who have had lesser responses. The intravenous form should not be administered with intravenous calcium. There is preliminary 
evidence that ceftriaxone is reasonably safe during pregnancy and nursing. It is a thirdgeneration cephalosporin that acts by inhibiting bacteria from building a cell wall.

Inhibiting the SHV-1 and TEM families of bacterial -lactamases, tazobactam is a medicinal medication used to treat antibiotic-resistant bacteria. The sodium version, tazobactam sodium, is the most often used form of this antibiotic. To put it simply, it's a component that may be introduced into some antibiotics in order to make them less susceptible to the development of resistance by bacteria. Piperacillin/tazobactam is a combination of tazobactam and piperacillin that is used to treat infections caused by Pseudomonas aeruginosa ${ }^{[22-23]}$. Tazobactam enhances the potency of piperacillin by making it effective against bacteria that produce -lactamase ${ }^{[24]}$, which would otherwise destroy piperacillin. Tazobactam is a penicillin sulfone that has undergone extensive modification.

Simultaneous determination of Ceftriaxone and Tazobactam using HPLC was found in the current study.

Till now, there have only one UPLC method and no HPLC reports available for the estimation of Tazobactam and Ceftriaxone. Hence, we employed HPLC method to determine both drugs.

\section{Experimental Study}

\section{Solutions and Reagents}

HPLC grade of Acetonitrile, Water-HPLC graded were procured Merck Ltd. Worli, in Bombay, India. From Glenmark Pharmaceuticals, APIs of Ceftriaxone and Tazobactam as reference standards were procured.

\section{Collection of instruments}

Waters alliance liquid chromatography (model 2695) monitored with empower 2.0 data handling system and a detector of photo diode array (model 2998) was used for this study.

\section{Buffers are chosen}

Water.

\section{Step of mobility}

For Standard review, the mobile step was water as buffer in a 40:60 (v/v) acetonitrile mixture and was degassed beforehand. A mobile phase chosen to produce well-defined peaks with a low tailing factor (2.0) and a plate count of over 2000 was selected.

\section{Prepare the diluent}

Acetonitrile and Water (50:50). 


\section{Conditions of Chromatography}

For the HPLC experiments, Waters X-Terra RP-18 (150 x $4.6 \mathrm{~mm}, 2.1 \mu \mathrm{m})$ was used. The elution was conducted with isocratic conditions using acetonitrile: water (60:40 by volume) at a flow rate of $1.0 \mathrm{ml} / \mathrm{min}$. The injection volume was $10 \mu \mathrm{l}$, and the run time was 5 minutes, with the column temperature set to room temperature and the absorbance measured at $230 \mathrm{~nm}$ (Because maximum absorbance was observed at this wavelength. So, this was selected as wavelength).

\section{Standard Solution Preparation}

Weigh 100mg of Ceftriaxone and $12.5 \mathrm{mg}$ of Tazobactam carefully. These working standards were placed in a $100 \mathrm{ml} \mathrm{VF}, 70 \mathrm{ml}$ diluent was applied, and the contents were sonicate for 10 minutes to dissolve the contents. Using diluent, dilute $5 \mathrm{ml}$ of the above solution to $50 \mathrm{ml}$.

\section{Sample Solution}

Using diluent, dilute $112.5 \mathrm{mg}$ of sample (equivalent to $100 \mathrm{mg}$ of Ceftriaxone and 12.5 $\mathrm{mg}$ of Tazobactam) to volume in a $100 \mathrm{ml}$ volumetric flask. Filter the solution with a 0.45 nylon syringe filter. Using diluent, dilute $5 \mathrm{ml}$ of the above solution to $50 \mathrm{ml}$.

\section{Validation Process}

\section{System Precision}

The system's performance has been validated through assessment of device suitability parameters. Limits were found to be met for a variety of parameters, including plate count, tailing, and RSD percentage.

\section{Specificity}

Being able to identify and test a given analyte in the presence of other elements required to be combined in the Standard and the standard solution is known as specificity. Blank Standards and those with Tazobactam and Ceftriaxone will be tested using chromatograms.

\section{Accuracy}

Being close to the real meaning of the technique is what defines accuracy. Three concentrations will be used to test the recovery trials. The drug's quantity, percentage of recovery, and standard deviations were calculated after every injection at each level.

\section{Precision}

It is the level of agreement between the various test results that determines the precision of the analytical methodology. Researchers examined the effects of sampling a homogeneous population more than once. The current process was evaluated in terms of its ability to provide repeatable, intraday, and inter-day results. It was examined by sampling the materials on the same day and over the course of different days. 


\section{Linearity}

Linearity is the feature of analytical process which allows for a direct proportion of analytical results in response to a certain concentration of the analyte in the Standard. A total of seven series of standard solutions were selected for the assessment of the linearity spectrum. The calibration curve was drawn by comparing regular solution concentration with peak area. Using the least square method, the slope, intercept, and coefficient of correlation were calculated.

\section{Forced Degradation}

The peaks in the chromatogram should agree. ICH guidance Q1(A) R2 was performed in conjunction with stress degradation experiments. The peaks of degradation should be well distanced and at least 1.0 resolution between peaks. For the largest peaks to go over, a separation must occur. A degradation of around 20 percent has been attained via several various stress conditions like acid, alkali, peroxide, reduction, thermal and photo in what is known as a forced degradation experiment.

\section{Robustness}

Robustness refers to a procedure's resistance to small process parameter changes, as well as its reliability in normal operation. An organic solution was introduced into the HPLC system for a robustness analysis, and the chromatographic settings (such as flow rate and mobile-phase organic content) were modified. The separation factor, retention time, and peak asymmetry were determined by evaluating the effects of altered parameters.

\section{Results and Discussion}

The aim of this study is to establish a single isocratic HPLC method for the simultaneous quantification of Tazobactam and Ceftriaxone in bulk and pharmaceutical dosage forms that is reliable, precise, and cost effective. According to the UV spectra of these compounds, an appropriate wavelength for simultaneous estimation of two drugs was chosen.

\section{Optimization of the method}

Using buffers $(0.1 \%$ orthophosphoric acid, $0.1 \%$ formic acid, $0.1 \%$ triethylamine and water) and acetonitrile as mobile phase different trials were conducted in isocratic and gradient modes. Various stationary phases including phenyl, biphenyl, amino, $\mathrm{C}_{18}$, and $\mathrm{C}_{8}$, were used to test the system. The resolution and retention times were improved by changing the mobile step composition at each trial. In the end, the separation was achieved using a waters X-terra RP-18 column $(150 \mathrm{~mm} \times 4.6 \mathrm{~mm}, 2.1 \mu \mathrm{m})$ and a mobile phase of water: acetonitrile (40:60 v/v) with a flow rate of $1.0 \mathrm{ml} / \mathrm{min}$ and UV detection at a wavelength of $230 \mathrm{~nm}$. The entire performance lasted five minutes. Conditions for optimized chromatography are provided in table 1. 


\section{System Suitability}

To attain results, the following device suitability parameters were established after six consecutive injections of normal solution: theoretical plate number, time, peak area, tailing factor, and resolution. The chromatogram in Figure 1 was the representative of the suitability results detailed in table 2 .

Table 1. Method suitability conditions

\begin{tabular}{|c|c|}
\hline Parameter & Suitable conditions \\
\hline Column & Waters X-Terra RP-18 $(150 \times 4.6 \mathrm{~mm}, 2.1 \mu)$ \\
\hline Moving Phase & Water: Acetonitrile $(40: 60 \mathrm{v} / \mathrm{v})$ \\
\hline Volume of injection & $10 \mu \mathrm{mL} / \mathrm{min}$ \\
\hline Stream rate & $25^{\circ} \mathrm{C}$ \\
\hline Temperature of column & $230 \mathrm{~nm}$ \\
\hline Wavelength & 5 minutes \\
\hline Time duration & $3.131 \mathrm{~min}$ \\
\hline Retention time of Tazobactam & $2.648 \mathrm{~min}$ \\
\hline Retention time of Ceftriaxone & \\
\hline
\end{tabular}

Table 2. Results of system suitability

\begin{tabular}{|c|c|c|}
\hline Parameter & Tazobactam & Ceftriaxone \\
\hline Number of plates & 7885 & 3471 \\
\hline Tailing & 1.06 & 1.02 \\
\hline Resolution & - & 3.21 \\
\hline Peak elution time & 3.131 & 2.648 \\
\hline \% RSD & 0.13 & 0.2 \\
\hline
\end{tabular}

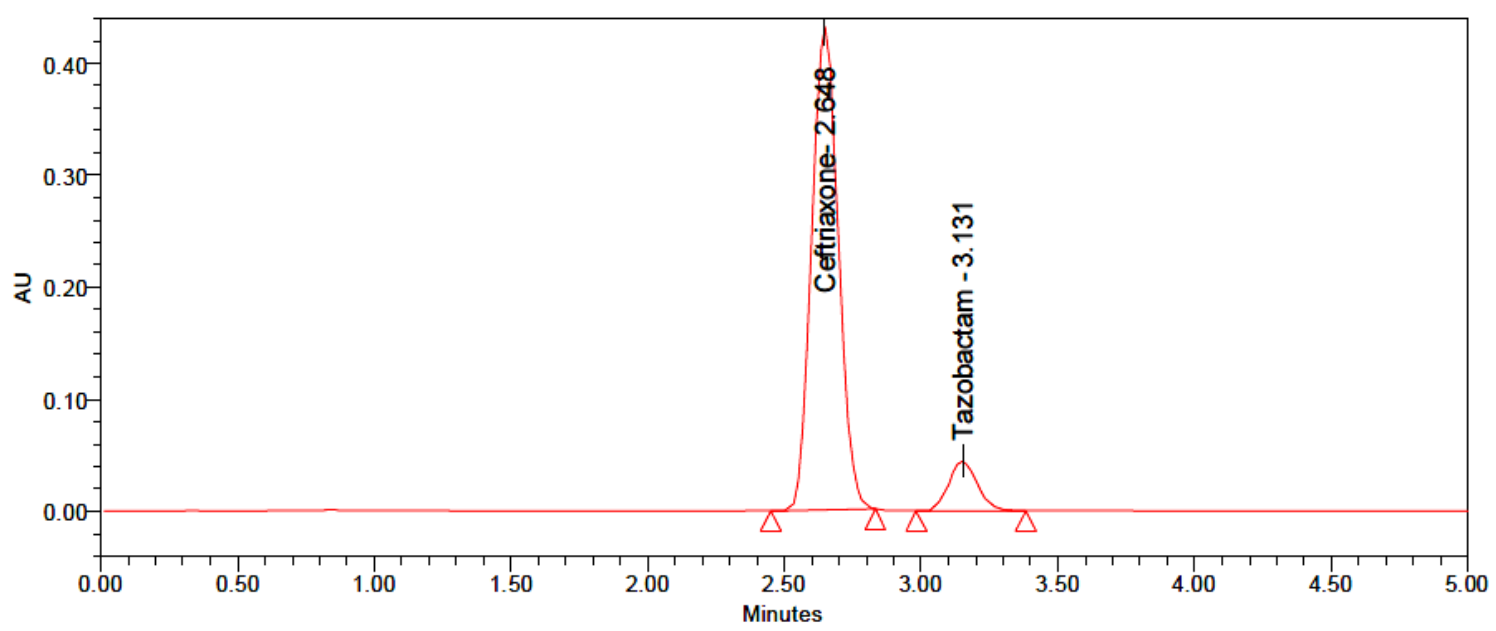

Figure 1. Chromatogram of standard

\section{Specificity}

There was no participation from Tazobactam and Ceftriaxone at the elution time. As seen in Figure 2, the blank chromatogram is present. 


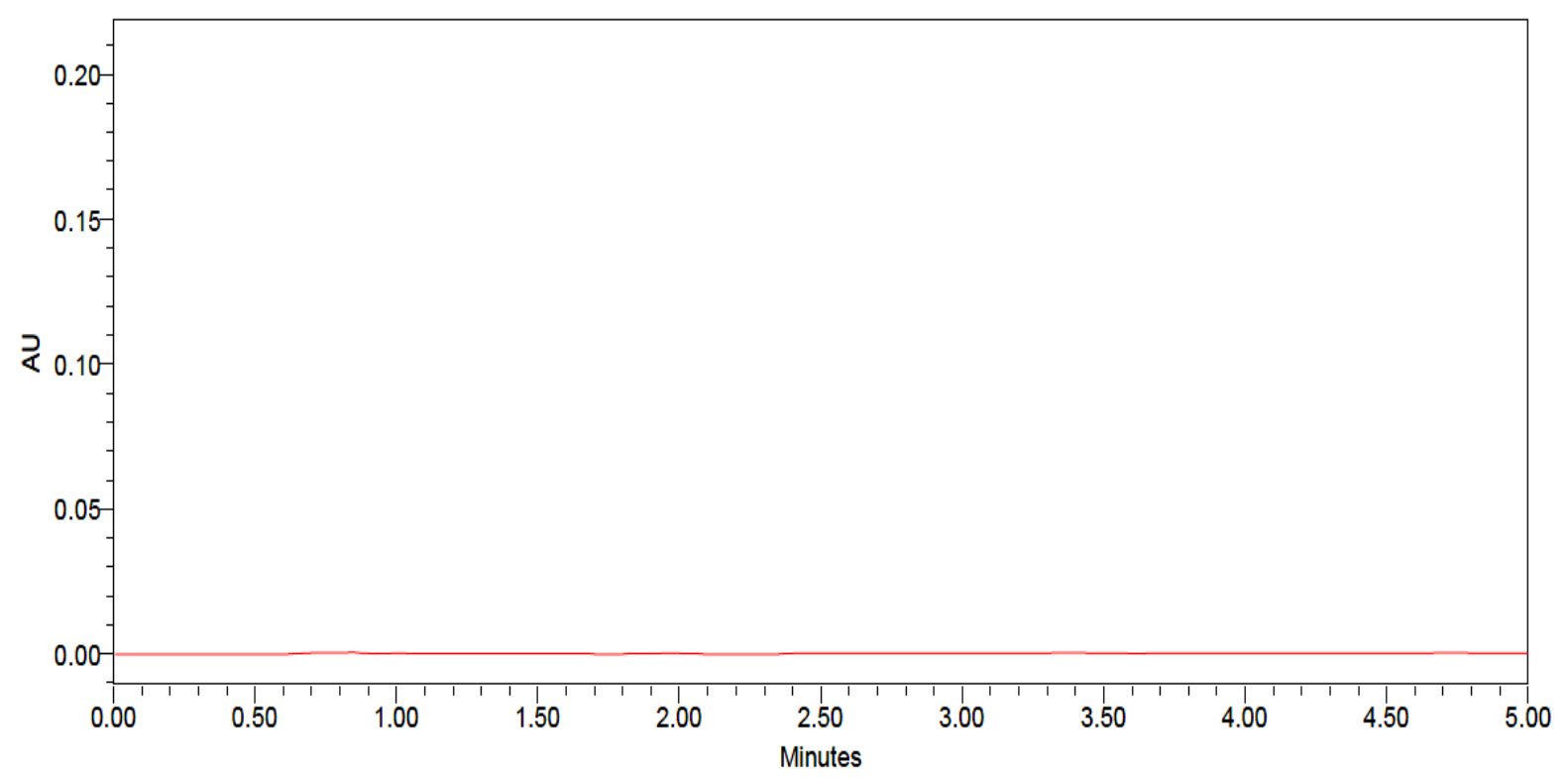

Figure 2. Chromatogram of blank

\section{Linearity}

By using a calibration curve to determine the linearity of the area of peak, its corresponding concentration was discovered. From this graph, it appears that the range of $1.25-18.75 \mu \mathrm{g} / \mathrm{mL}$ of Tazobactam and $10-150 \mu \mathrm{g} / \mathrm{mL}$ of Ceftriaxone had a straight line. For Tazobactam, the equations of regression were $\mathrm{Y}=34346 \mathrm{x}+35\left(\mathrm{R}^{2}=0.9998\right)$ and $\mathrm{Y}=28491 \mathrm{x}+9335\left(\mathrm{R}^{2}=0.9999\right)$ for Ceftriaxone, respectively. Linearity results were demonstrated in table 3 .

Table 3. Results of linearity

\begin{tabular}{|c|c|c|c|c|}
\hline \multirow{2}{*}{ S. No. } & \multicolumn{2}{|c|}{ Ceftriaxone } & \multicolumn{2}{c|}{ Tazobactam } \\
\cline { 2 - 5 } & $\begin{array}{c}\text { Concentration } \\
(\mu \mathrm{g} / \mathrm{mL})\end{array}$ & Region & $\begin{array}{c}\text { Concentration } \\
(\mu \mathrm{g} / \mathrm{ml})\end{array}$ & Region \\
\hline 1 & 10.00 & 285541 & 1.25 & 30589 \\
\hline 2 & 25.00 & 745621 & 3.13 & 75896 \\
\hline 3 & 50.00 & 1427452 & 6.25 & 153846 \\
\hline 4 & 100.00 & 2854143 & 12.50 & 307586 \\
\hline 5 & 125.00 & 3589652 & 15.63 & 378965 \\
\hline 6 & 150.00 & 4268745 & 18.75 & 452896 \\
\hline Slope & \multicolumn{2}{|c|}{28491} & \multicolumn{2}{c|}{34346} \\
\hline Intercept & \multicolumn{2}{|c|}{9335} & & \multicolumn{2}{c|}{0.9998} \\
\hline CC & \multicolumn{2}{|c|}{09996} & & \\
\hline
\end{tabular}




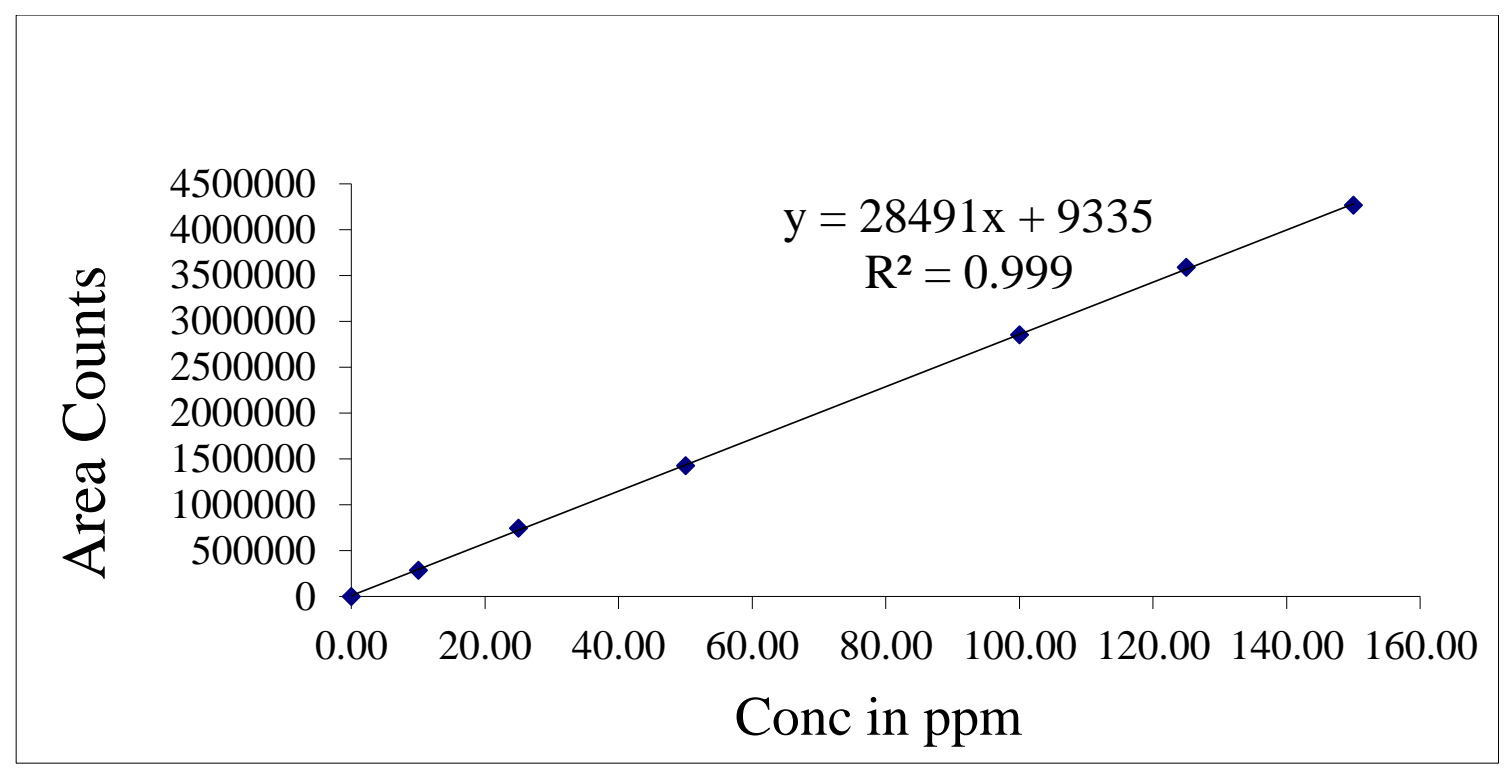

Figure 3. Linearity plot of Ceftriaxone

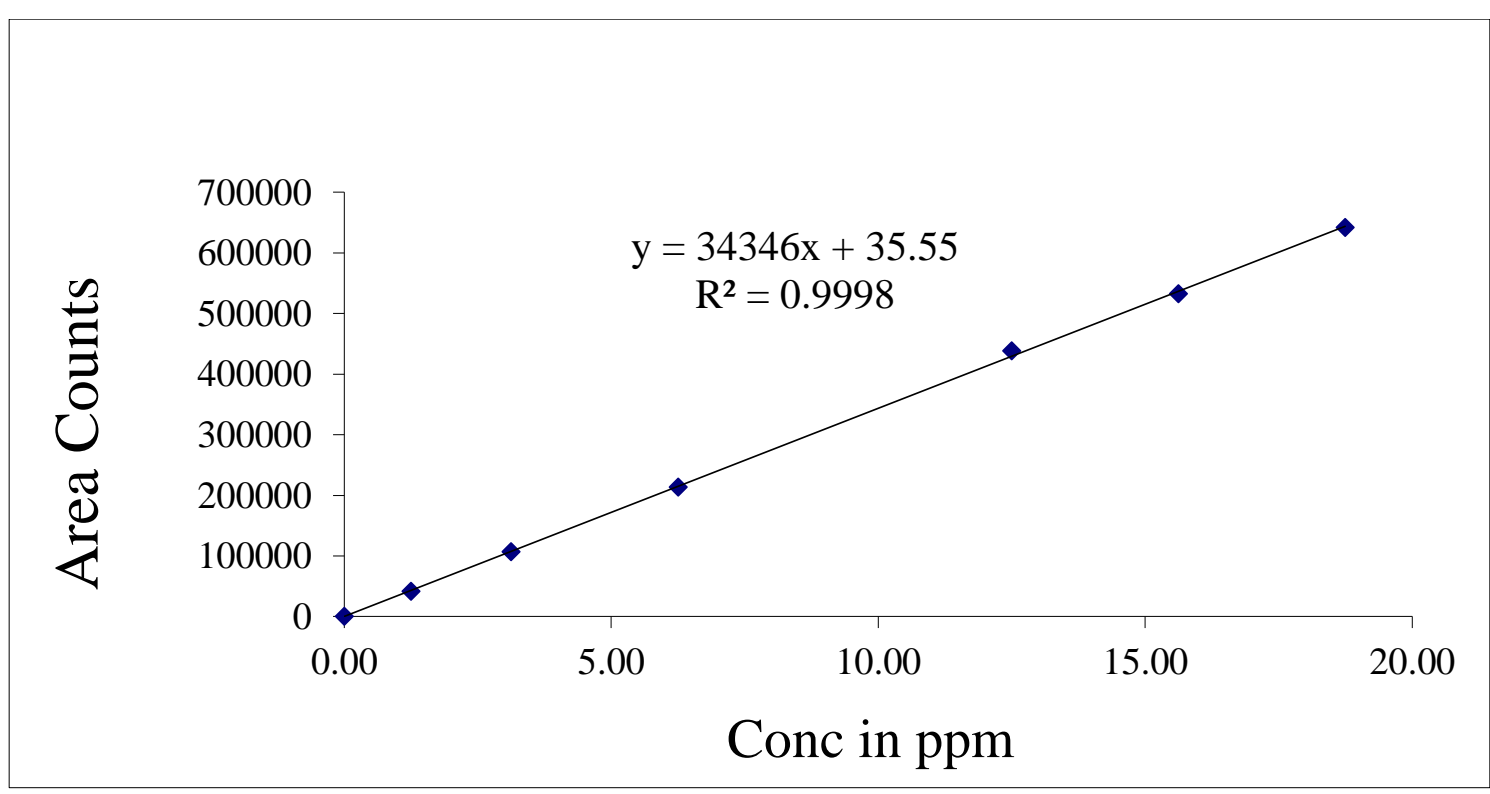

Figure 4. Linearity plot of Tazobactam

\section{Precision}

Intraday and intermediate precision variances were assessed in relation to the procedure's accuracy. The samples were examined six times on the same day to obtain intraday results for Tazobactam and Ceftriaxone. The system's intermediate precision was explored by analyzing data in the same laboratory using a variety of examiners and tools. It is very accurate, with an RSD percentage of less than $2 \%$. The process was precise, yielding the best drug recoveries at each additional concentration. Table 4 shows the method precision results. 
Table 4. Outcomes of Method precision

\begin{tabular}{|c|c|c|}
\hline S. No & Region of Ceftriaxone & Region of Tazobactam \\
\hline 1 & 2857694 & 307903 \\
\hline 2 & 2869618 & 306948 \\
\hline 3 & 2865051 & 308919 \\
\hline 4 & 2844807 & 302971 \\
\hline 5 & 2872570 & 307586 \\
\hline 6 & 2874662 & 309714 \\
\hline Mean & 2864067 & 307340 \\
\hline Std dev & 11206.244 & 2355.77 \\
\hline$\%$ RSD & 0.39 & 0.76 \\
\hline
\end{tabular}

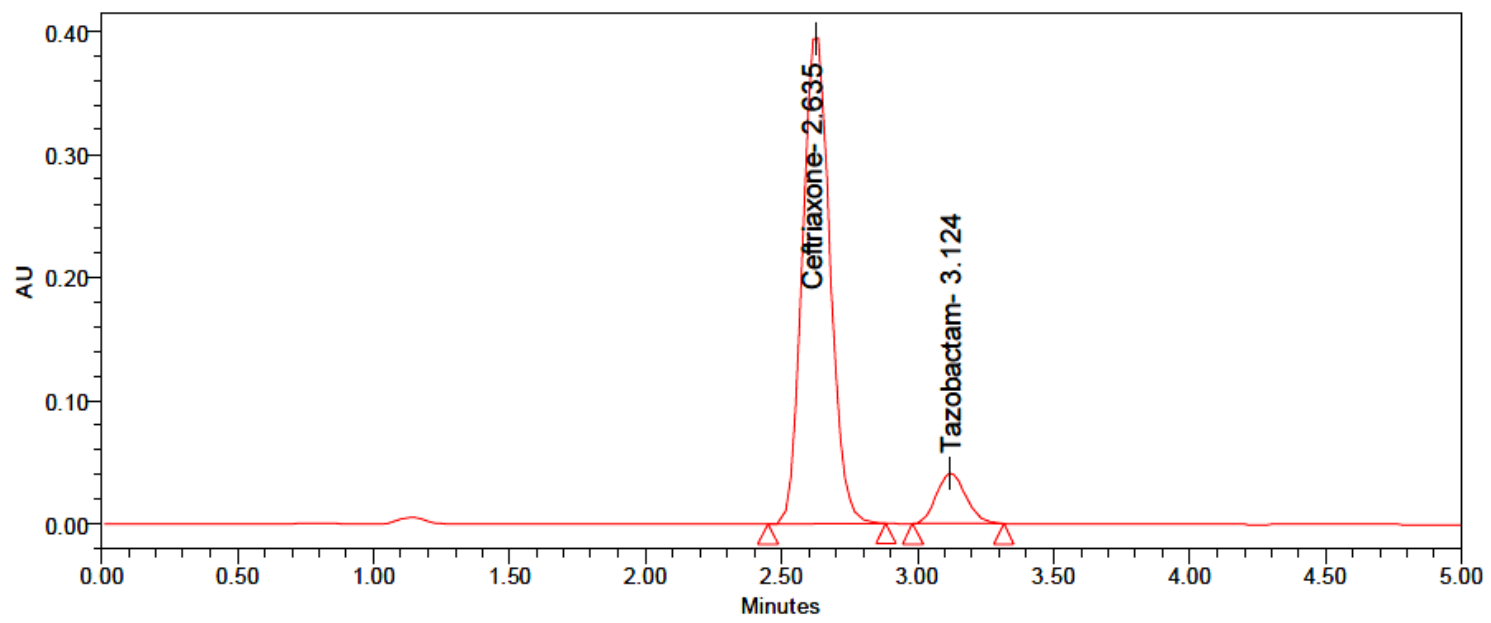

Figure 5. Chromatogram of method precision

\section{Intermediate Precision (Ruggedness)}

Intermediate precision results were shown in table 5.

Table 5. Results of intermediate precision

\begin{tabular}{|c|c|c|c|c|}
\hline \multirow{2}{*}{ S. No } & \multicolumn{2}{|c|}{ Ceftriaxone } & \multicolumn{2}{c|}{ Tazobactam } \\
\cline { 2 - 5 } & $\begin{array}{c}\text { Area at } \\
1^{\text {st }} \text { day }\end{array}$ & $\begin{array}{c}\text { Area at } 2^{\text {nd }} \\
\text { day }\end{array}$ & $\begin{array}{c}\text { Area at } 1^{\text {st }} \\
\text { day }\end{array}$ & $\begin{array}{c}\text { Area at } 2^{\text {nd }} \\
\text { day }\end{array}$ \\
\hline 1 & 2854025 & 2867748 & 304303 & 305315 \\
\hline 2 & 2861457 & 2836819 & 306496 & 309564 \\
\hline 3 & 2843183 & 2847054 & 305178 & 304471 \\
\hline 4 & 2853887 & 2824289 & 307618 & 308125 \\
\hline 5 & 2876320 & 2897152 & 305550 & 303648 \\
\hline 6 & 2922192 & 2850513 & 312263 & 317502 \\
\hline Mean & 2868510 & 2853929 & 306901 & 308104 \\
\hline Std dev & 28487.19 & 25649.20 & 2862.61 & 5124.20 \\
\hline$\%$ RSD & 0.99 & 0.89 & 0.93 & 1.66 \\
\hline
\end{tabular}




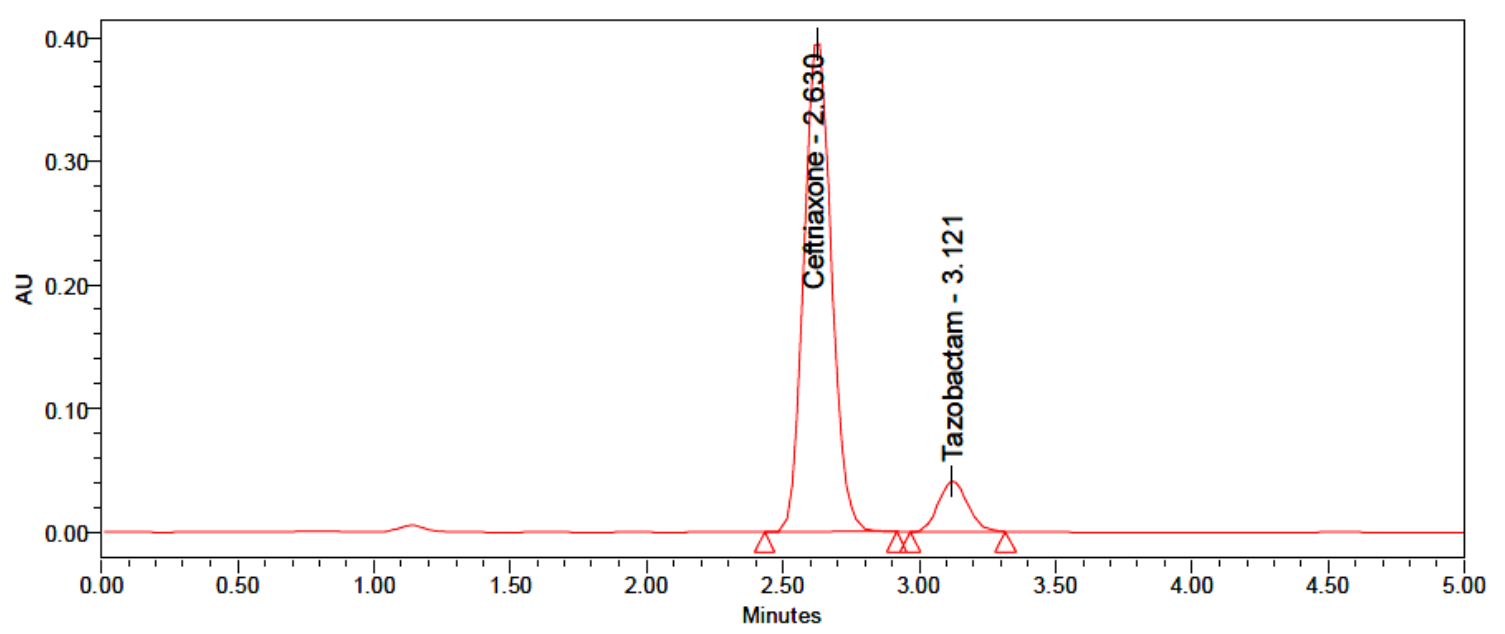

Figure 6. Chromatogram of intermediate precision

\section{Accuracy}

By measuring the recovery experiments at three stages, the method's precision was reached (50 percent, 100 percent, and 150 percent). APIs were made with concentrations of Tazobactam of $6.25,12.50$, and $18.75 \mathrm{micrograms} / \mathrm{mL}$ and Ceftriaxone of 50, 100 and 150 micrograms $/ \mathrm{mL}$. For each stage of the spike, the test solution was injected three times, and the assay was performed in accordance with the test process. In addition to being able to determine the percentage of recovered data, the mean and relative standard deviations have also been found. The strategy was effective because the recovery values fell within the target range. Table 6 presents the accuracy results.

Table 6.Results of accuracy

\begin{tabular}{|c|c|c|c|c|}
\hline Accuracy & $\begin{array}{c}\text { Amount of } \\
\text { Tazobactam }\end{array}$ & $\begin{array}{c}\% \\
\text { Recovery }\end{array}$ & $\begin{array}{c}\text { Amount of } \\
\text { Ceftriaxone }\end{array}$ & $\begin{array}{c}\% \\
\text { Recovery }\end{array}$ \\
\hline $50^{*}$ & 6.25 & 100.5 & 50 & 100.4 \\
\hline $100^{*}$ & 12.5 & 100.2 & 100 & 100.2 \\
\hline $150^{*}$ & 18.75 & 100.0 & 150 & 100.5 \\
\hline
\end{tabular}

* Results are mean recovery of three sample preparations

\section{LOD and LOQ}

The concentration level at which the analytes are reliably detected and quantified is the limit of detection and quantification. Tazobactam and Ceftriaxone had a LOD concentrations of $0.38 \mu \mathrm{g} / \mathrm{ml}, 3.0 \mu \mathrm{g} / \mathrm{ml}$ and their $\mathrm{S} / \mathrm{N}$ values of 3,3 . The LOQ concentrations of Tazobactam and Ceftriaxone were $1.25 \mu \mathrm{g} / \mathrm{ml}, 10 \mu \mathrm{g} / \mathrm{ml}$, and their $\mathrm{S} / \mathrm{N}$ values were 10,10 . ( $\mathrm{S} / \mathrm{N}$ is the ratio of signal to noise).

\section{Robustness}

To ensure the robustness of the chromatographic technique, the researchers evaluated flow rate and the composition of the mobile phase. By changing the flow rate and mobile phase ratio, the area of drugs changes. So, the percentage of relative standard deviation 
changes. Here in Table 7 (robustness results) the \%RSD values are in within the acceptable limit.

Table 7. Outcomes of robustness

\begin{tabular}{|c|c|c|c|c|}
\hline Drug Name & $\begin{array}{c}\text { Flow Plus } \\
(1.1 \mathrm{ml} / \mathrm{min}) \\
\% \mathrm{RSD}\end{array}$ & $\begin{array}{c}\text { Flow Minus } \\
(0.9 \mathrm{ml} / \mathrm{min}) \\
\% \mathrm{RSD}\end{array}$ & $\begin{array}{c}\text { Organic Plus } \\
(66: 34) \\
\% \mathrm{RSD}\end{array}$ & $\begin{array}{c}\text { Organic Minus } \\
(54: 46) \\
\% \mathrm{RSD}\end{array}$ \\
\hline Ceftriaxone & 0.52 & 0.74 & 0.51 & 0.58 \\
\hline Tazobactam & 1.32 & 0.94 & 0.73 & 1.07 \\
\hline
\end{tabular}

\section{Forced Degradation}

The proposed approach can be used for successful evaluations of release and stability tests, and it can be called a stability preferable technique. Acid, Alkali, oxidation, reduction, photo, and thermal degradation are all included in the ICH-required forced degradation analysis. The chromatograms show that the selected drugs remained stable under the stress conditions, despite the presence of degraded peaks. Results of forced degradation were given in table 8 and 9 , forced degradation chromatograms were shown in figure 4.

\section{Acid degradation:}

$5 \mathrm{ml}$ of sample stock was moved to such a $50 \mathrm{ml} \mathrm{VF}$, which was then filled with $1 \mathrm{~mL}$ of $1 \mathrm{~N} \mathrm{HCl}$ and held for 15 minutes. After 15 minutes, add $1 \mathrm{~mL} 1 \mathrm{~N} \mathrm{NaOH}$ and dilute to the desired strength with solvents. Then it was injected into HPLC system.

\section{Alkali degradation:}

$5 \mathrm{ml}$ of sample stock was moved to such a $50 \mathrm{ml} \mathrm{VF}$, which is now being filled with 1 $\mathrm{mL}$ of $1 \mathrm{~N} \mathrm{NaOH}$ and held for 15 minutes. After 15 minutes, add $1 \mathrm{~mL} 1 \mathrm{~N} \mathrm{HCl}$ and dilute to the desired strength with diluents. Then it was injected into HPLC system.

\section{Peroxide degradation:}

Move $5 \mathrm{ml}$ of specimen to such a $50 \mathrm{ml} \mathrm{VF}$ and apply $1 \mathrm{ml}$ of $30 \%$ peroxide solution. Made up to the mark with diluents after 15 minutes. Then it was injected into HPLC system.

\section{Reduction degradation:}

$5 \mathrm{ml}$ of sample stock was transferred into $50 \mathrm{ml} \mathrm{VF}$, add $1 \mathrm{ml}$ of $30 \%$ sodium bi sulphate solution and dilute to the desired strength with solvents. Then it was injected into HPLC system. 


\section{Heat degradation:}

For 6 hours, the sample stock solution was baked at $105^{\circ} \mathrm{C}$, the resulting solution was dilute to the desired strength with solvents. Then it was injected into HPLC system.

\section{Photolytic degradation:}

For 6 hours, the sample solution was exposed to sunlight, the resulting solution was dilute to the desired strength with solvents. Then it was injected into HPLC system.

\section{Hydrolysis degradation:}

$5 \mathrm{ml}$ of sample stock was transferred into $50 \mathrm{ml} \mathrm{VF}$, add $1 \mathrm{ml}$ of HPLC water and dilute to the desired strength with solvents. Then it was injected into HPLC system.

Table 8. FD results

\begin{tabular}{|c|c|c|}
\hline Degradation & \% Deg of Ceftriaxone & \% Deg of Tazobactam \\
\hline Control & 0.1 & 0.2 \\
\hline Acid & 12.8 & 13.4 \\
\hline Alkali & 13.7 & 12 \\
\hline Peroxide & 13.2 & 14.4 \\
\hline Reduction & 11.5 & 10.7 \\
\hline Thermal & 6.8 & 4.2 \\
\hline Photo & 2.6 & 3.4 \\
\hline Hydrolysis & 1.9 & 2.2 \\
\hline
\end{tabular}

\section{Conclusion}

For the analysis of Ceftriaxone and Tazobactam in pharmaceutical formulations, the established approach is accurate, precise, and reliable. The uniformity, correctness, reliability, and resilience and forced deterioration of Ceftriaxone and Tazobactam drug. All the RSDs were less than 2, indicating that the approach is accurate and that the findings obtained by this approach are in good agreement. Moreover, this approach can also be used to improve pharmaceutical formulation of Ceftriaxone and Tazobactam drug.

\section{Acknowledgement}

The authors want to thank Shree Icon Pharmaceutical Laboratories for giving them all the necessary equipment to finish their work.

\section{Conflicts of Interest}

None 


\section{Funding Support}

None

\section{References}

[1] Zhanel, G G., Chung, P., Adam, H., Zelenitsky, S., Denisuik, A., Schweizer, F., Lagacé-Wiens, P R., Rubinstein, E., Gin, A S., Walkty, A., Hoban, D J., Lynch Jp, $3^{\text {rd }}$, Karlowsky, J A. (2014). Ceftolozane/tazobactam: A novel cephalosporin/ $\beta$-lactamase inhibitor combination with activity against multidrug-resistant gram-negative bacilli. Drugs, 74(1), 31-51.

[2] Pichichero, Michael E. (2006). Cephalosporins can be prescribed safely for penicillin-allergic patients. The Journal of Family Practice, 55(2), 106-12.

[3] Fernandes, P., Martens, E. (2017). Antibiotics in late clinical development. Biochemical Pharmacology, 133, 152-163.

[4] Mashalidis, EH., Lee, SY. (2020). Structures of Bacterial MraY and Human GPT Provide Insights into Rational Antibiotic Design. Journal of Molecular Biology, 432(18), 4946-4963.

[5] Ghosh, C., Sarkar, P., Issa, R., Haldar, J. (2019). Alternatives to Conventional Antibiotics in the Era of Antimicrobial Resistance. Trends in Microbiology, 27(4), 323338.

[6] Njuguna, B., Gardner, A., Karwa, R., Delahaye, F. (2017). Infective Endocarditis in Low- and Middle-Income Countries. Cardiology Clinics, 35(1), 153-163.

[7] Ambrosioni, J., Hernandez-Meneses, M., Téllez, A., Pericàs, J., Falces, C., et al. (2017). The Changing Epidemiology of Infective Endocarditis in the Twenty-First Century. Current Infectious Disease Reports, 19(5), 21.

[8] Mount, Hillary R., Boyle, Sean D. (2017). Aseptic and Bacterial Meningitis: Evaluation, Treatment, and Prevention. American Family Physician, 96(5), 314-322.

[9] Wall, EC., Ajdukiewicz, KM., Bergman, H., Heyderman, RS., Garner, P. (2018). Osmotic therapies added to antibiotics for acute bacterial meningitis. The Cochrane Database of Systematic Reviews, 2, CD008806.

[10] Llamas-Álvarez, AM., Tenza-Lozano, EM., Latour-Pérez, J. (2017). Accuracy of Lung Ultrasonography in the Diagnosis of Pneumonia in Adults: Systematic Review and Meta-Analysis. Chest, 151(2), 374-382.

[11] Schuetz, P., Wirz, Y., Sager, R., Christ-Crain, M., Stolz, D., Tamm, M., et al. (2018). Effect of procalcitonin-guided antibiotic treatment on mortality in acute respiratory infections: a patient level meta-analysis. The Lancet. Infectious Diseases, 18(1), 95-107.

[12] Sartelli, Massimo., Viale, Pierluigi., Catena, Fausto., et al., (2013). 2013 WSES guidelines for management of intra-abdominal infections. World Journal of Emergency Surgery, 8(1), 3.

[13] Wang, Yun Fei., Que, Hua Fa., Wang, Yong-Jun., Cui, Xue Jun. (2014). Cochrane Wounds Group (ed.). Chinese herbal medicines for treating skin and soft-tissue infections. Cochrane Database of Systematic Reviews, (7), CD010619. 
[14] Zhanel, George G., Zhanel, Michael A., Karlowsky, James A. (2020). Oral and Intravenous Fosfomycin for the Treatment of Complicated Urinary Tract Infections. The Canadian Journal of Infectious Diseases \& Medical Microbiology, Hindawi Limited, 2020, 1-11.

[15] Morgan, MK., Decker, CF. (2016). Gonorrhea. Disease-a-Month, 62(8), 260-8.

[16] Savaris, Ricardo F., Fuhrich, Daniele G., Maissiat, Jackson., Duarte, Rui V., Ross, Jonathan. (2020). Antibiotic therapy for pelvic inflammatory disease. The Cochrane Database of Systematic Reviews, 2020(8), CD010285.

[17] May, JR., Dolen, WK. (2017). Management of Allergic Rhinitis: A Review for the Community Pharmacist. Clinical Therapeutics, 39(12), 2410-19.

[18] Wilcox, C., Turner, J., Green, J. (2014). Systematic review: the management of chronic diarrhoea due to bile acid malabsorption. Alimentary Pharmacology \& Therapeutics, 39(9), 923-39.

[19] Hill, Anita., Hill, Quentin, A. (2018). Autoimmune hemolytic anemia. Hematology, 2018(1), 382-389.

[20] Saggio, ML., Crisp, D., Scott, JM., Karoly, P., Kuhlmann, L., Nakatani, M., et al. (2020). A taxonomy of seizure dynamotypes. eLife, 9, e55632.

[21] Pravettoni, V., Incorvaia, C. (2016). Diagnosis of exercise-induced anaphylaxis: current insights. Journal of Asthma and Allergy, 9, 191-198.

[22] Johnson, PA. (2019). Novel understandings of host cell mechanisms involved in chronic lung infection: Pseudomonas aeruginosa in the cystic fibrotic lung. Journal of Infection and Public Health, 12(2), 242-246.

[23] Nguyen, AT., Jones, JW., Ruge, MA., Kane, MA., Oglesby-Sherrouse, AG. (2015). Iron Depletion Enhances Production of Antimicrobials by Pseudomonas aeruginosa. Journal of Bacteriology, 197(14), 2265-75.

[24] Bush, K. (2018). Past and Present Perspectives on $\beta$-Lactamases. Antimicrobial Agents and Chemotherapy, 62(10), e01076-18. 